\title{
ANTIOXIDANT AND ANTIMICROBIAL ACTIVITIES OF CITRUS LEMON PEELS ENCAPSULATED IN PVA
}

\author{
Anjalie.K.Nair ${ }^{1}$, Madhura Mukherjee ${ }^{1}$, Saptaki Nag$^{1}$, M.Pandimadevi ${ }^{1 *}$ \\ ${ }^{1}$ Department of Biotechnology, School of Bioengineering, SRM IST, Kattankulathur \\ *pandimadevi2008@gmail.com
}

https://doi.org/10.34302/crpjfst/2019.11.2.9

\begin{tabular}{ll}
\hline $\begin{array}{l}\text { Article history: } \\
\text { Received: }\end{array}$ & ABSTRACT \\
27 February 2019 & In this study, waste lemon peels were converted into a dietary supplement. \\
Accepted: & Lemon peels were used because of the abundance of phytochemicals \\
10 May 2019 & present in it and also they are easily available throughout the year. To \\
improve the therapeutic efficacy, we used Polyvinyl Alcohol (PVA) as a \\
nanocarrier of lemon peel methanolic extract. The lemon peel extract was \\
Keywords: \\
encapsulated in PVA by the solvent evaporation method, to improve the \\
DPPH; & solubility and stability of the compounds in the extract. Characterization of \\
Nanoformulation; & the prepared lime peel nanoformulation (LP-NF) was done by Scanning \\
PVA; & Electron Microscope, Zeta potential and Fourier Transform Infrared \\
Sodium Alginate. & techniques. The antioxidant assays like DPPH(2,2-diphenyl-1- \\
& picrylhydrazyl) radical scavenging assay and hydrogen peroxide assay \\
& showed a high scavenging activity when compared with commercial \\
& supplement with the IC50 value of $24 \pm 0.05$ and $26.07 \pm 0.11$ respectively. \\
The Gram-negative bacteria, E. coli showed a zone of inhibition of 18 mm \\
indicating the antibacterial property of LP-NF. The percentage release of \\
the nanoformulation from sodium alginate beads was calculated and it \\
showed the release of nanoparticle up to $83 \%$ after 7 hours in PBS at pH \\
7.4.
\end{tabular}

\section{Introduction}

Fruits and vegetable processing industries produce a large amount of wastes every year. The byproducts of fruits such as peels and pulp of many fruits are sources of sugars, minerals, organic acids, dietary fibres and phenolics (Sand et al., 2006).Pulp and seed contribute to the bulk of the fruit weight, comprising about $46 \%$ and $44 \%$, while peel constitutes about 10\%. Phytochemicals are non-dietary plant compounds such as carotenoids, flavonoids, isoflavonoids and phenolic acids. These phytochemicals play an important role in protecting cells against oxidative stress caused by harmful free radicals, which cause damage of biomolecules, such as DNA, lipids and proteins (Rui H et al., 2004). Citrus fruits also contain an impressive list of other essential nutrients, including both glycaemic and nonglycaemic carbohydrate (sugars and fibre), potassium, folate, calcium, thiamin, niacin, vitamin $\mathrm{C}$ and vitamin $\mathrm{B}_{6}$, phosphorus, magnesium, copper, riboflavin, pantothenic acid and a variety of phytochemicals(Prasad et al., 2010). Bioactive compounds such as antioxidants like flavonoids, phenolic compounds and ascorbic acid are necessary for human nourishment. Flavanones, flavones and flavonols are three sorts of flavonoids that are abundantly present in Citrus fruit. The important types of flavonoids present in citrus fruits are naringin, narirutin and hesperidin. Essential flavonoid components like flavanones, flavanone glycosides and poly methoxylated flavones are novel to citrus fruits and are comparatively uncommon in other plants (Grohmann K et al., 2001). The peels of citrus fruits especially citrus 
lemon are a great source of organic acids, polyphenolic compounds and dietary fibres. These compounds have a wide range of actions such as antioxidants, antibacterial, antiviral and cardio preventive activities. Lemon peels have shown to have protective effects against mouth, lung, skin, breast and colon cancer in many animal studies (Sheila et al., 2001). Utilisation of Citrus by-products as a source of polyphenols and antioxidants might have substantial financial profit to food processors and therefore an economical, efficient, and environmentally safe application of these wastes is required (Balasundram $\mathrm{N}$ et al., 2006).Studies show that the different bioactive compounds present in these peels are effective towards various bacteria (Keles et al., 2001).

Antioxidants are molecules that destroy free radical reactions and inhibit cellular damage. Overproduction of free radicals in the human body can cause a disparity that may lead to oxidative damage to large biomolecules such as lipids, DNA, and proteins. This damage causes pathogenesis of several human diseases like Cardiovascular Disease, certain types of cancers, and ageing (Gershoff, 1993; Haratset al., 1998; Jacques et al., 1997). Phenolic compounds are secondary metabolites of plants, which have antioxidant activities (Suryaprakash et al., 2000).Antioxidant activity depends on the extract concentration and increasing concentrations of extract correspond to increase in antioxidant activity. Grape seed extracts are known to have natural antioxidants, such as tocopherol and ascorbic acid and it was found that there was a difference in activity, depending on the assay. The superoxide anion scavenging activity was determined to be dependent on flavanol concentration (Yamaguchi et al. 1999).Diseases like cancer, diabetes, high blood pressure are more likely related to dietary habits. Functional foods recently have earned a lot of importance because they tend to reduce the occurrence of these diet-related diseases. Studies suggest that consuming foods like fruits and vegetables prevent our cells from oxidative damage, and are free scanvengers, help in preventing stressinduced diseases such as cardiac disorders, inflammatory and neurodegenerative diseases (Kaur C et al., 2001, Prakash etal.,2007). Antioxidants are used as food additives as they have the tendency to protect the food from spoilage (Soma Singh et al., 2014).

It was reveaed that the diets high in fruits and vegetables may decrease the risk of chronic diseases, such as cardiovascular disease and cancer, and phytochemicals including phenolics, flavonoids and carotenoids from fruits and vegetables play a key role in reducing such chronic disease risk (Rui H et al., 2004).Phytochemicals from pomegranate (Punicagranatum L) are known to stop cancer cell proliferation and cell apoptosis through the activation of cellular transcription factors and signaling proteins (Sand et al., 2006).Phytochemicals are known to have multiple antimicrobial mechanisms which include damaging the microbial cell wall, cytoplasmic membrane, etc. Reactive oxygen species (ROS) accumulation, Phosphatidylserineexternalization, DNA fragmentation are the few of the mechanisms of a photochemical induced death of cells. Exploiting the ability of phytochemical ought to encourage the advancement of better antimicrobial procedures which could effectively control the human infectious diseases (Omojate $\mathrm{G}$ et al., 2014).Extraction of natural antioxidants from orange, lemon and pomegranate fruit peels is done by using methanol as the solvent. Each extract was then utilised in paneer to determine the shelf life and antioxidant activity of value added paneer (Soma Singh et al., 2014).Antibacterial activity of citrus peel extract is due to the presence of essential components including flavonoids, limonoids, essential oils, alkaloids, and lacrone hypericin are effective against a wide range of bacteria. Other potent compounds like alcohols, terpenes and esters add to the antibacterial impacts of essential oils (Keles O. et al., 2001).Recently there has been an increase in concern about the development of antimicrobial resistance of pathogenic bacteria. Citrus peel, a natural substance is 
said to have antimicrobial activities. The citrus peel contains various types of essential oils that repress the growth or kill pathogenic bacteria. Citrus peels were assessed for their ability to inhibit the growth of the pathogen like E.coli by well diffusion assay on MacConkey agar and a zone of $11 \mathrm{~mm}$ was obtained indicating that citrus derived essential compounds have potential applications as inhibitory agents against E.coli (Ramakrishna $\mathrm{N}$ et al., 2008). The factors like quality of the original plant, the geographic origin, climatic condition, harvesting date and storage affect the quality of natural extracts and their antioxidant properties (Cuvelier et al., 1996).The temperature during drying and extraction affects the compound stability due to chemical and enzymatic degradation (Ibaanez et al., 1999).Temperature and light are the major factors affecting phytochemical compounds. These factors affect different compounds like flavonoids, carotenoids and terpenoids to different extents. Hightemperature exposure to these phytochemicals can cause a reduction in free- radical scavenging activity (Larrauri et al., 1998).For the isolation of antioxidants from plants, solvent extraction is more frequently used. The yield of extraction and antioxidant activity of extracts are highly dependent on the polarity of solvents used, because different antioxidant potential of compounds react with different polarity of solvents (Duh $P$ et al., 1995).For the extraction of orange peels, different solvents were used, the maximum total phenolic content was accomplished with methanol, whereas 50\% acetone extracted more specifically the leucoanthocyanins. Lower IC50 values for the DPPH radical (amount of antioxidant needed for causing a reduction of 50\% in the absorbance of DPPH) were observed for butanol extracts, followed by those in ethyl acetate (Julkunen-Tiitoa et al., 1985).For measuring the antioxidant activity of a particular substance, single assay can reflect the scavenging sources and antioxidants present in a system (Prior $\mathrm{R}$ et al., 2005).Generally important natural materials have been extracted with organic solvents and nonetheless, some of them are toxic, and the extraction conditions are often severe. Thus, a food grade ethanol rather than methanol is broadly utilizedin the extraction of phenolic compounds from different citrus peels (Li B at al., 2006).Antioxidant activity of a plant extract can be measured with different tests with different mechanisms. Chemical methods are based on the ability of extracts to scavenge different free radicals. UVabsorption and chelation ability are responsible for the antioxidant activity in oily systems. Tests measuring the scavenging activity with different challenges, for example, superoxide radical $\left(\mathrm{O}_{2}\right)$, hydroxyl $(\mathrm{OH})$, nitric oxide (NO), alkyl peroxy radicals, ABTS+ (radical cation of 2, $20-$ azinobis, 3 ethylbenzothiozoline-6sulphonate), (2, 2-diphenyl-1-picrylhydrazyl) (DPPH) have been developed (Butler J et al., 1993).

In spite of the fact that, plants have huge potential as therapeutic compounds, its effectiveness and oral bioavailability is constrained by poor solubility and poor formulation characteristics because of high lipophilicity.Techniques used for preparing nanoparticles from biodegradable polymers are emulsion solvent evaporation, nanoprecipitation, salting out procedure, and a combined method. Nano-encapsulation of drugs/ plant extracts in biodegradable polymers like PVA (Poly Vinyl Alcohol), PCL (Polycaprolactone) has got consideration as a conceivable drug carrier system due to its faster mobility, high drug loading capacity and the possibility of controlled drug release to the specific target site. Moreover, these biodegradable polymers are approved by US Food and Drug Administration (FDA) and its final degradation products such as lactic and glycolic acids are perfect and safe, as they are either discharged by the kidneys or enter the Krebs' cycle to be in the end of the process eliminated as carbon dioxide and water (Leo E et al., 2004).Medicinal plants work at a very high dose, and these limitations can be addressed by formulating a suitable dosage form, that could offer better therapeutic 
effectiveness at low doses. Drugs from plant origin require an approach which can avoid administration of high dose and also increase patient compliance. One such attempt is nanoparticle formulation. Several studies are reported for the incorporation of different phytoconstituents in the form of nanoparticles (Trickler W et al., 2008). Recently phytochemicals have been used greatly as a nutraceutical in pharmaceutical and food formulations. Even though lemon peels have great ability as a therapeutic compound, its effectiveness is poor because of its poor solubility and oral bioavailability. This issue can be fixed by converting the lemon peel extracts to lemon peel nanoparticle. Nanoparticles can be formed or prepared by various types of methods. Preparing nanoparticles from biodegradable polymers can be prepared using different methods like emulsion solvent evaporation, salting out technique, and nanoprecipitation. Nanotechnology has become an important part of the food industry. This technique has the ability to change sensory characteristics, change the nutritional functionality of the food product, change colour, flavour and also can enhance the shelf life of the food product (Ganesan S et al., 2014).

Nanoencapsulation uses the emulsion solvent evaporation method to capture or entrap essential compounds into a carrier, for transporting it to the target site and for releasing the compounds in a sustained manner (Chiu et al., 2007). Plant origin drugs require such an approach, which avoids administration of high dose and also increases the patient compliance.

Encapsulation of essential compounds of citrus species, into carriers or matrices helps in the protection, transport and release of the compounds in a controlled manner. Likewise, encapsulation could be utilised to increase the shelf life of materials for controlled delivery of essential compounds when ingested in the digestive system over a scope of physiological conditions (Gharsallaoui A et al., 2007).

Nanoparticle antioxidants are another form of therapies which are used for the prevention and treatment of diseases occurring due to oxidative stress (Chelarama et at., 2014). Nanoparticle antioxidants due to its size have effective and sustained interactions with biomolecules and work strongly against free radical-induced cell damage. These nanoparticles have shown a high-performance therapeutic activity in constricting oxidative stress with potential applications in treating and preventing neurodegenerative conditions (Wang $\mathrm{J}$ et al., 2009).Despite being a powerful bioactive agent and natural antioxidant, few fruit peels like pomegranate are practically waterinsoluble. A solution to this issue would be the development of formulations of pomegranate peel nanoparticles to enhance its stability. The higher water-solubility could be ascribed to a larger surface area in contact with the solvent. The nanoformulation of the pomegranate had an antimicrobial effect stronger than the pure extract (Anand P et al., 2007).Polymers from normal sources have been utilised broadly in the pharmaceutical and nourishment industry. Among these polymers, polysaccharides have been broadly used in view of their biocompatibility, biodegradability, and low harmfulness). Alginate, a water-soluble, the natural polysaccharide consist of linear polysaccharide comprising of $\beta$-Dmannuronic acid and $\alpha$-L glucuronic acid deposits combined together in blocks which are regularly utilised because of its mucoadhesive properties and its capacity to form matrix systems and can be gelled through ionic or covalent cross-linking. The alginate-based hydrogel systems are extremely effective in capturing and controlled delivery of various essential components like drugs, proteins, enzymes and cells (Poncelet $\mathrm{R}$ et al., 1992). The alginate matrices basically encapsulate nanoparticles and as the alginate loaded nanoparticles pass through stomach fluids at different $\mathrm{pH}$, where there is a sustained release of the nanoparticles (Kawabata et al., 2010).Encapsulation of the drug loaded polymer nanoparticles into alginate- matrices provide protection and stability to drug amid 
its transit along the gastrointestinal tract, in this manner increasing the amount of drug accessible to apply its pharmacological effect. Besides, the presence of alginate in the developed hydrogel matrices permits sustained release of the drug as the particles go down the gastrointestinal tract (George $\mathrm{M}$ et al., 2007).The aim of this study is to produce a high dietary nano supplement from waste lemon peels and determining its antioxidant, antimicrobial properties and incorporation of this nano supplement into alginate beads and checking thein vitro release activity.

\section{Materials and methods}

\subsection{Collection of material}

The lemon peels were collected from the local juice shop. The lemon peels were washed well-using tap water. The peels were cut into small pieces, then it was kept under the sun for drying over a period of 3-5 days. The dried samples were powdered using a mixiegrinder. The powder of the peels was stored separately in airtight bottles (Asia et al., 2015).

\subsection{Preparation of extracts}

\subsubsection{Soxhlet extraction}

The $25 \mathrm{~g}$ powdered sample was extracted using $500 \mathrm{ml}$ of methanol at room temperature by Soxhlet extraction apparatus for 6 hours. The mixture was filtered through a Whatman filter paper and evaporated under reduced pressure at $60^{\circ} \mathrm{C}$ by a rotary evaporator. The extracts were placed in dark bottles and stored in the refrigerator at $4{ }^{\circ} \mathrm{C}$ for further use (Hegazy et al., 2012).

\subsection{Preliminary Phytochemical Analysis}

The powered lemon peels were subjected to the following preliminary phytochemical screening tests(Kaur et al., 2013).

- Test for Saponins: $2 \mathrm{ml}$ of the extract added with $6 \mathrm{ml}$ of distilled water.

- $\quad$ Test for Phytosterols: 4-5 drops of extracts, added with $1 \mathrm{ml}$ Chloroform and few drops of concentrated sulphuric acid.
- Test for Flavanoids: 2 to 4 drops of ferric chloride added with $0.5-1 \mathrm{ml}$ of the extracts.

- Test for Phenols: $1 \mathrm{ml}$ of the extract added with $5 \mathrm{ml}$ of Folin's reagent and $4 \mathrm{ml}$ of sodium carbonate.

- Test for Steroids: $0.5 \mathrm{ml}$ of extract added with $3 \mathrm{ml}$ of chloroform and $2 \mathrm{ml}$ of concentrated sulphuric acid.

- Test for Tannins: $1 \mathrm{ml}$ of extract added with few drops of $1 \%$ ferric chloride.

- Test for Terpenoids: $5 \mathrm{ml}$ of extract added with $2 \mathrm{ml}$ of chloroform and $3 \mathrm{ml}$ of sulphuric acid.

- $\quad$ Test for Cardiac glycosides: $5 \mathrm{ml}$ of extract added with $2 \mathrm{ml}$ of glacial acetic acid with 1 drop of ferric chloride added with concentrated sulphuric acid.

- Test for Amino acids: $1 \mathrm{ml}$ of extract added with few drops of ninhydrin.

\subsection{Determination of total phenolics content}

Total phenolic content (TPC) was measured using gallic acid for the calibration curve. Results are presented as Gallic Acid Equivalents (GAE). The total phenol content was determined according to FolinCiocalteu's reagent method. $0.5 \mathrm{ml}$ of extract and $0.1 \mathrm{ml}$ of $0.5 \mathrm{~N}$ FolinCiocalteu's reagent was mixed and the mixture was incubated at room temperature for $15 \mathrm{~min}$. Then $2.5 \mathrm{ml}$ of $20 \%$ sodium carbonate solution was added and further incubated for $30 \mathrm{~min}$, at room temperature and the absorbance was measured at $765 \mathrm{~nm}$. Gallic acid was used as a positive control. Total phenol values are expressed in terms of gallic acid equivalent for lemon peel ( $\mathrm{mg}$ of gallic acid/g of extracted compound) (Kamtekar et al., 2014).

\subsection{Preparation of lemon peels nanoformulation (LPNF) of methanolic extract}

LPNF were prepared by solvent evaporation technique (Shreedhara, C.S et al., 2017).1:3 ratio of Lemon peel extract to Polyvinyl Alcohol (PVA) was used in this method. Briefly, $30 \mathrm{mg}$ of PVA was dissolved in $10 \mathrm{~mL}$ milliQ water. $10 \mathrm{mg}$ of 
the lemon peel methanolic extract was dispersed in $10 \mathrm{~mL}$ acetone. The dispersed lemon peel methanolic extract in acetone was added drop wise to the PVA solution on a magnetic stirrer. The resulting mixture was kept on the magnetic stirrer for the organic solvent to evaporate. The suspension formed was homogenised using high-speed homogenizer at different time intervals and then sonicated using different sonicator parameters. Centrifugation was done at 2300 rpm for 30 minutes at room temperature. The supernatant was separated by centrifugation at $18000 \mathrm{rpm}$ for $30 \mathrm{~min}$ in a cooling ultracentrifuge at $4{ }^{\circ} \mathrm{C}$. LPNF appeared as a sediment, which was separated and resuspended in milliQ water. and freeze-drying was done by adding $2 \%$ mannitol. Nanoparticles thus formed were evaluated for yield, particle size and zeta potential.

\subsection{Characterization Studies:}

\subsubsection{Determination of Yield (\%):}

The nanoparticles were weighed and the practical yield was calculated using the following equation:

Yield $\%=$ (Weight of nanoparticles obtained / Weight of extract and polymer used) $\times 100$

\subsubsection{Shape and surface morphology:}

Shape and surface morphology of the nanoformulation was measured byHigh Resolution Field Emission Electron Microscope at an acceleration voltage of 5-20 KV.

\subsubsection{Zeta potential:}

Zeta potential was measured using Horiba Nanoparticle analyser. It is used for evaluating the surface zeta potential of the nanoparticles. The Zetasizer Nano ZS is a high performance two angle particles and molecular size analyser for the enhanced detection of aggregates and measurement of small or dilute samples, and samples at very low or high concentration using dynamic light scattering.

\subsubsection{FT-IR Spectroscopy:}

FTIR analysis of the nanoformulation was done using FTIR spectrophotometer by Agilent Technologies- Cary 600 series. The spectrum was recorded in the region of 4000 to $400 \mathrm{~cm}-1$. The FTIR spectra was compared with the FTIR spectra of the extract and PVA.

\subsection{In vitro antioxidant properties}

\subsubsection{Determination of DPPH (1-1-diphenyl}

2- picrylhydrazyl) radical scavenging activity

DPPH radical scavenging assay was performed according to the method of Rekha S et al., (2013) and absorbance was measured at $517 \mathrm{~nm}$ using a spectrophotometer. Percentage inhibition and IC50 values were calculated with respect to control. Ascorbic acid was used as the standard. $0.1 \mathrm{mM}$ of DPPH solution was prepared in methanol and $1.0 \mathrm{ml}$ of this solution was added to $1.0 \mathrm{ml}$ different concentrations $(10-50 \mu \mathrm{g} / \mathrm{ml})$ of nanoformulation. After incubation for 30 minutes, the absorbance was measured at 517 $\mathrm{nm}$ against blank. Ascorbic acid was used as the reference standard. Radical scavenging activity was expressed as the percentage of inhibition and was calculated using the following formula:

$$
\text { \%Inhibition }=\left[\left(\mathrm{A}_{\mathrm{o}^{-}} \mathrm{A}_{\mathrm{t}}\right) / \mathrm{A}_{\mathrm{o}}\right] \times 100
$$

Here, $A_{o}$ was the absorbance of the blank (without nanoformulation) and $A_{t}$ was the absorbance of nanoformulation. All the tests were performed in triplicate.

\subsubsection{Scavenging Hydrogen Peroxide:}

The ability of the nanoformulation to scavenge hydrogen peroxide was determined according to the method of Bhakya $S$ et al., (2016). A solution of hydrogen peroxide $(40 \mathrm{mM})$ was prepared in phosphate buffer at $\mathrm{pH} 7.4$ and concentration was determined spectrophotometrically at $230 \mathrm{~nm}$. Nanoformulation at different concentrations $(10-50 \mu \mathrm{g} / \mathrm{ml})$ in distilled water was added to $0.6 \mathrm{ml}$ of hydrogen peroxide solution and the absorbance of the mixture was read at $230 \mathrm{~nm}$ after 20 minutes against a blank solution in phosphate buffer without hydrogen peroxide. The percentage of scavenging activity of hydrogen peroxide of nanoformulation and 
the control is calculated using the following equation:

$$
\text { \% Inhibition }=[(\text { Ao- At }) / \text { Ao }] \times 100
$$

Here, Ao was the absorbance of the blank (without nanoformulation) and At was the absorbance of nanoformulation. All the tests were performed in triplicate.

\subsection{Antibacterial Activity:}

LPNF was tested against Escherichia coli for antibacterial activity by agar well diffusion method. and this was performed by determining the zone of inhibition. Pure cultures were subcultured into a nutrient broth and incubated at $37^{\circ} \mathrm{C}$ for $24-48$ hours. The test organism was spread uniformly on the individual plates using spread plate technique. Three wells of $5 \mathrm{~mm}$ diameter were made on the agar plate. Using sterile micropipette tips, $0.1 \mathrm{~mL}(100 \mu \mathrm{L})$ of the sample solution was pipetted into each of the wells in all the plates. After incubation at $37^{\circ} \mathrm{C}$, the diameters of zone of inhibition were measured after 24hours (Kokila $\mathrm{T}$ et al., 2015).

\subsection{Preparation of Sodium Alginate Beads:}

Sodium alginate solution at $3 \mathrm{wt} \%$ was freshly prepared. The alginate powder was dissolved in double-distilled water while mixing with a magnetic stirrer. Lemon peel nanoformulation (LP-NF) was added to the alginate solution. The alginate solution containing LP-NF was dropped using a syringe through a 20 -gauge needle into $0.5 \mathrm{M}$ $\mathrm{CaCl}_{2}$ solution. Ionically cross-linked alginate beads were formed and cured in the $\mathrm{CaCl}_{2}$ solution for $30 \mathrm{~min}$ at room temperature. The alginate beads were then collected by filtration and gently washed twice with deionized water (Kim et al., 2005).

\subsection{In-vitro drug release study}

The release of LP-NF from the sodium alginate beads was performed in 0.1M PBS. $\mathrm{pH} 2.1$ (gastric $\mathrm{pH}$ ) and $\mathrm{pH}$ 7.4(intestinal $\mathrm{pH}$ ) of PBS were considered for this study.The first 2 hours were maintained at $\mathrm{pH} 2.1$ and the subsequent hours were maintained at $\mathrm{pH}$ 7.4 at $37^{\circ} \mathrm{C}$. The prepared alginate beads in PBS were kept on a shaker. After anhour of incubation, aliquots were removed from the buffer solution, and wasanalysed by UV-Vis spectrophotometry at $\lambda_{\max }$ of $570 \mathrm{~nm}$. The percentage of LP-NF released was calculated from the standard graph of LP-NF in PBS at different concentrations such as $0,5,10,15$, 20, and $25 \mu \mathrm{g} / \mathrm{ml}$ (Guzman-Villanueva et al., 2013).

\section{Results and discussion}

Bioactive compounds are the main constituents in most fruits and vegetables and these are reported to contain antioxidant and free radical scavenging activities. Phenolics present in these bioactive compounds act as free radical scavengers which exhibit antioxidant activity by inhibiting lipid peroxidation and by preventing the oxidation of hydroperoxides. Flavonoids are one of the largest groups among the natural phenolics and are said to possess antioxidant properties acting as effective scavengers of harmful free radicals. Characterization of the prepared nanoformulation was done by scanning electron microscopy (SEM), Fourier transform Infrared Spectroscopy (FTIR) and Zeta potential.

\subsection{Phytochemical analysis:}

Different phytochemical tests were carried out. Figure 1 shows the result for phytochemical analysis followed by Table 1 which lists the presence or absence of the various phytochemicals in our lemon peel extracts.

Table 1.Phytochemical analysis of lemon peel extract in methanol. $(+)$ indicating the presence of phytochemical and (-) indicating absence of the phytochemical.

\begin{tabular}{|l|c|}
\hline Phytochemicals & Methanol \\
\hline Saponins & - \\
\hline Phytosterol & + \\
\hline Flavanoids & + \\
\hline
\end{tabular}




\begin{tabular}{|l|c|}
\hline Phenols & + \\
\hline Steroids & + \\
\hline Tannins & + \\
\hline Terpenoids & - \\
\hline Cardiac Glycosides & - \\
\hline Amino acids & - \\
\hline
\end{tabular}

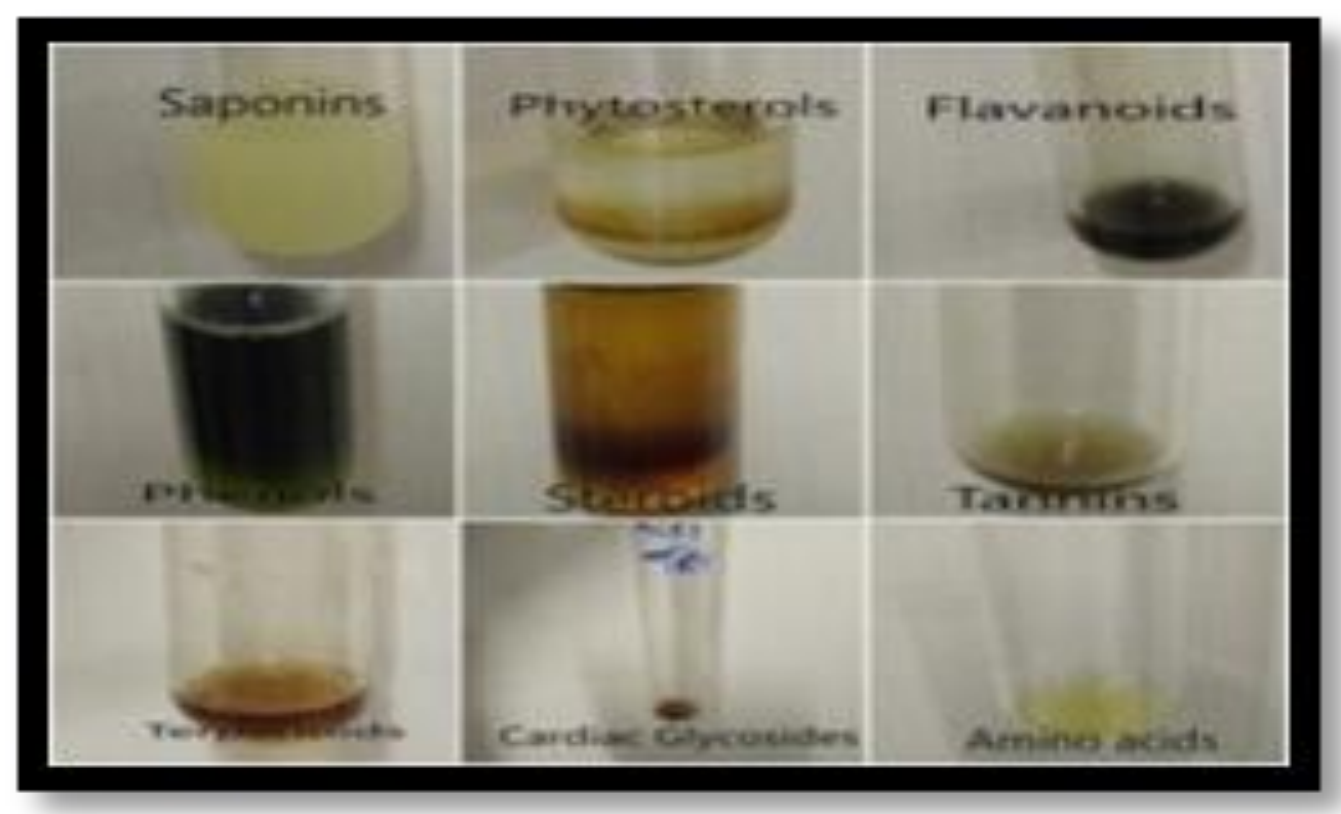

Figure 1.Phytochemical Test Results for Lemon peels

\subsection{Total phenolic content:}

In the present study, a high phenolic content of $0.923 \mathrm{GAE}$ was observed in the methanolic extract of Citrus limon peels. This high content of phenol contributes to its potential antioxidant property and curative ability by adsorbing and neutralizing free radicals. The results are in agreement with the studies of Samidha Kamtekar, S et al., 2014 where, higher phenolic content $(0.97$ \pm 0.11 GAE) was obtained in methanolic extracts of Citrus limon peels.

\subsection{Yield\%:}

Different batches of LP-NF were prepared and these were subjected to different sonication and homogenization variables. Yield percentage was calculated and it was found to be highest in LP-NF3 (11.5\%).

Table 2.Batches of Lime Nanoformulations subjected to different sonication and homogenization parameters.

\begin{tabular}{|l|l|l|l|l|l|}
\hline Batches & $\begin{array}{l}\text { LP-ME } \\
(\mathbf{m g})\end{array}$ & $\begin{array}{l}\text { PVA } \\
(\mathbf{m g})\end{array}$ & $\begin{array}{l}\text { Sonication } \\
(\mathbf{a} / \mathbf{t} / \mathbf{p})\end{array}$ & $\begin{array}{l}\text { Homogenization } \\
(\text { Seconds) }\end{array}$ & Yield (\%) \\
\hline LP-NF1 & 10 & 30 & $60 / 10 / 5$ & 10 & 7.2 \\
\hline LP-NF2 & 10 & 30 & $50 / 10 / 5$ & 10 & 8.3 \\
\hline LP-NF3 & 10 & 30 & $60 / 10 / 5$ & 20 & 11.5 \\
\hline LP-NF4 & 10 & 20 & $60 / 10 / 5$ & 10 & 8.5 \\
\hline LP-NF5 & 10 & 50 & $50 / 10 / 5$ & 20 & 7.8 \\
\hline
\end{tabular}

\subsection{Scanning Electron Microscopy:}

The scanning electron microscopy photographs showed the formulation of nanoparticles. The structure of the nanoparticles plays an important role in determining their adhesion, interaction and 
absorption with the body cells. It was shown

that the LP-NF displays a particle.

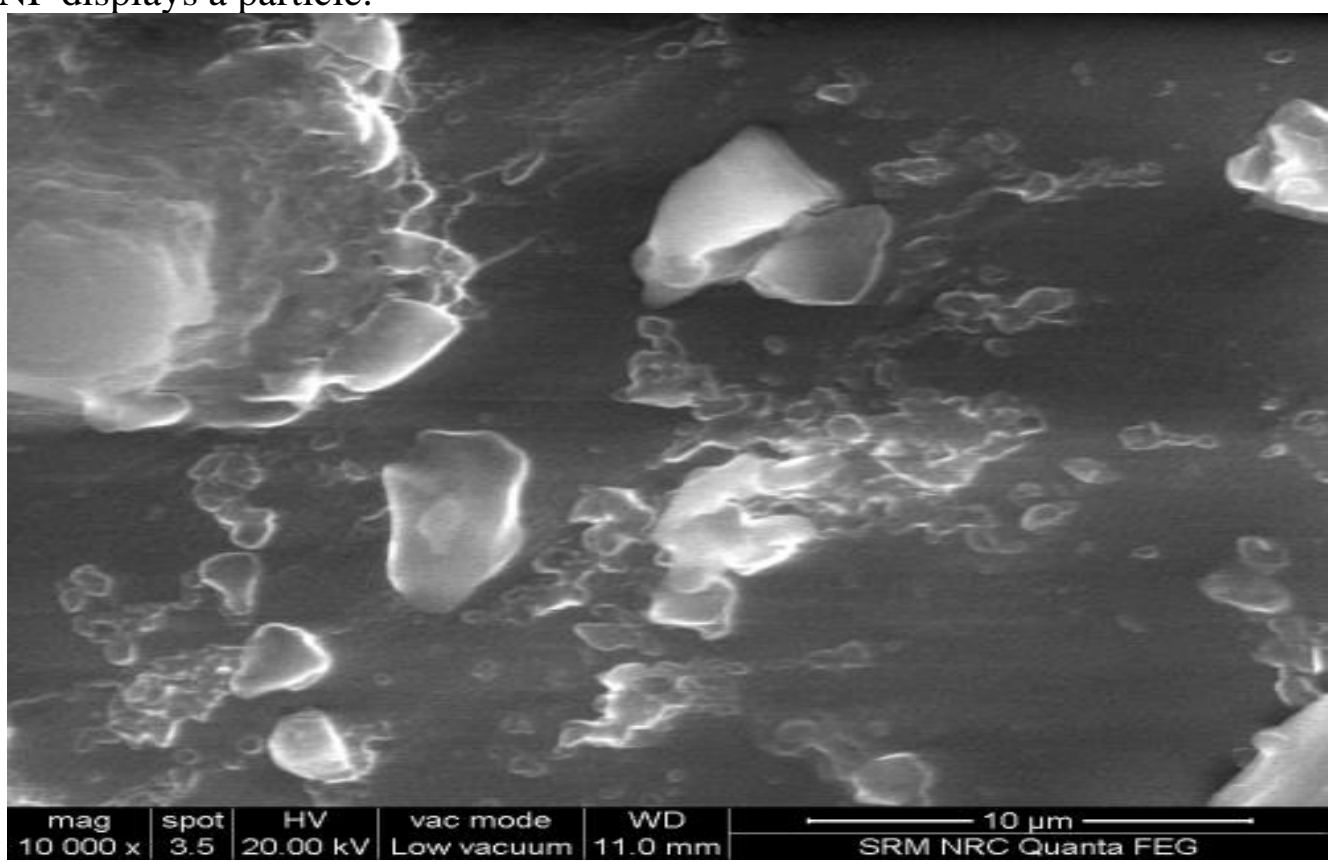

Figure 3.SEM image of LP-NF

\subsection{FTIR Characterization:}

The intermolecular interaction between PVA, Lemon peel methanolic extract and LPNF was determined by FTIR spectroscopy are shown (Fig.7 and 8). The characteristic spectra of the PVA polymer showed in the region $2918 \mathrm{~cm}^{-1}$ and $929 \mathrm{~cm}^{-1}$ due to $-\mathrm{CH}$ stretchingvibrations, carbonyl $-\mathrm{C}=\mathrm{O}$ stretching at $1735.53 \mathrm{~cm}^{-1}$ and $-\mathrm{OH}$ stretching at $3419.29 \mathrm{~cm}^{-1}$. The lemon peel extract spectra showed characteristic bands in the region $3418.14 \mathrm{~cm}^{-1}$ due to $-\mathrm{OH}$ stretching vibrations and also bands in the region $1732.65 \mathrm{~cm}^{-1}$ and $1076.39 \mathrm{~cm}^{-1}$ due to $\mathrm{C}=\mathrm{O}$ stretching vibrations. For LP-NF, the spectra showed that the $\mathrm{OH}$ stretching band (3200$3600 \mathrm{~cm}^{-1}$ ) is slightly shifted to a lower wave length. The IR band of at $1076.39 \mathrm{~cm}^{-1}$ can be attributed to the $-\mathrm{C}-\mathrm{O}-$ stretching vibrations of carboxylic acid, ester, and ether groups of the proteins present in the extract (LP-ME) and this peak shifted to $1095.56 \mathrm{~cm}^{-1}$ for LPNF. The spectra obtained for PVA nanoparticles showed characteristic bands that were consistent with the studies of (Sowmya et al 2017). The slight shift in the spectra of OH-stretching band (3200-3600 $\mathrm{cm}^{-1}$ ) for lemon peel loaded PVA nanoparticle may be due to increase in terms of energy absorption. These observations suggest that lemon peel methanolic extract is associated with the PVA polymer by hydrogen bonds. Also, the band corresponding for $\mathrm{C}=\mathrm{O}$ stretching (1700$1800 \mathrm{~cm}^{-1}$ ) was broader, indicating that the extract is associated with the PVA polymer by interactions between the carbonyl and the carboxyl groups of the flavonoids in the extract and the polymer 
Agilent Resolutions Pro

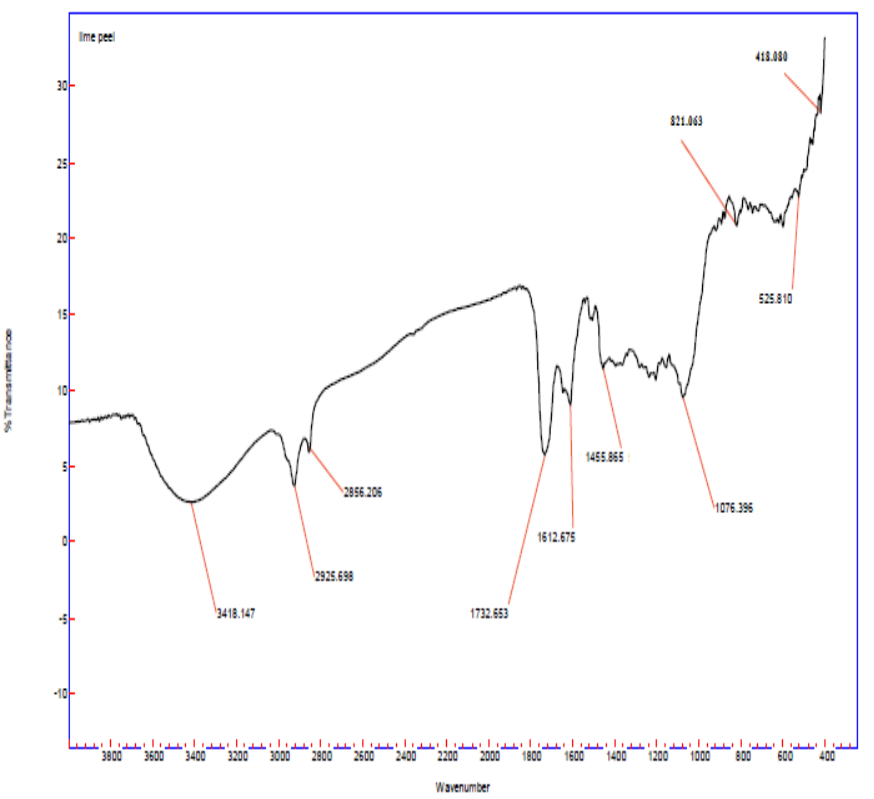

Figure 4.FTIR spectra of Lemon Peel Methanolic Extracts
Agilent Resolutions Pro

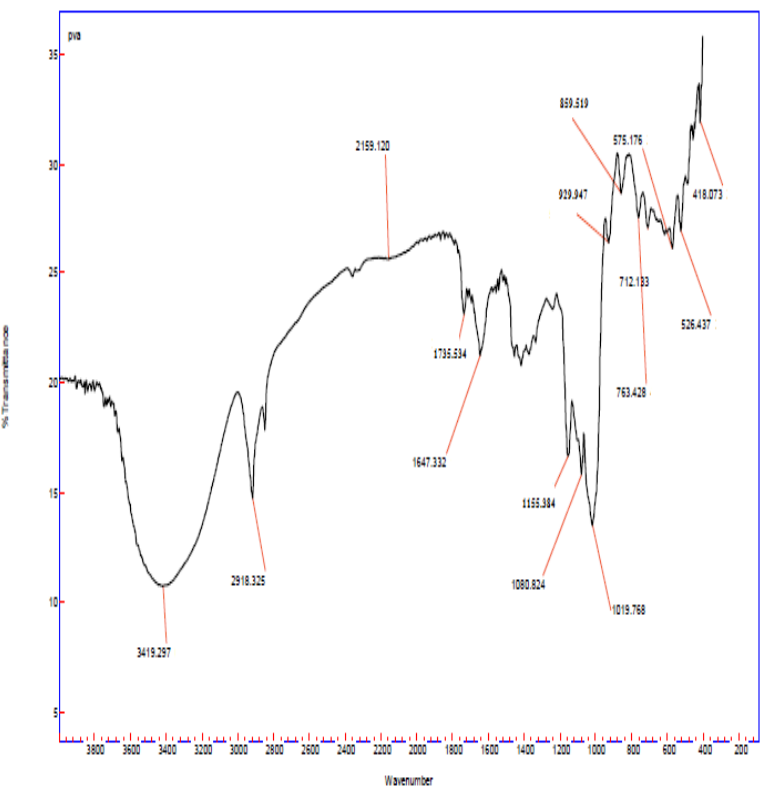

Figure 5.FTIR spectra of PVA
Agilent Resolutions Pro

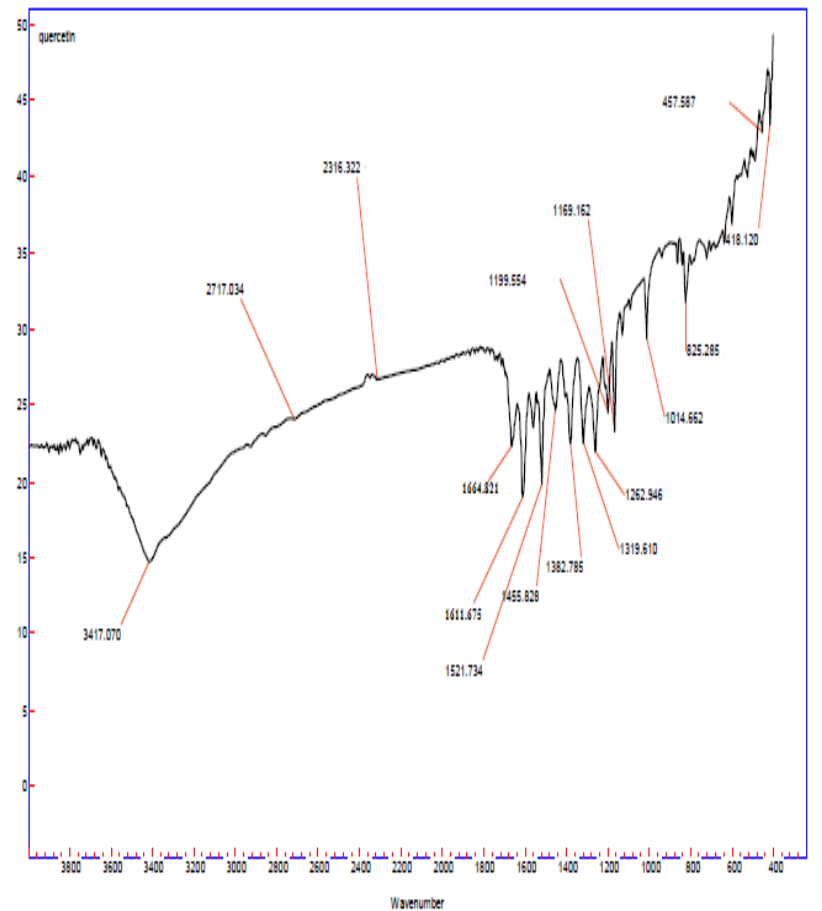

Figure 6. FTIR Spectra of Quercetin

\subsection{ZETA POTENTIAL:}

Zeta potential of the LP-NF was found to be $-28.3 \mathrm{mV}$ (Fig.8). Nanoparticles with zeta potential values greater than $+25 \mathrm{mV}$ or less than $-25 \mathrm{mV}$ are said to have high degrees of stability. As the observed zeta potential of the

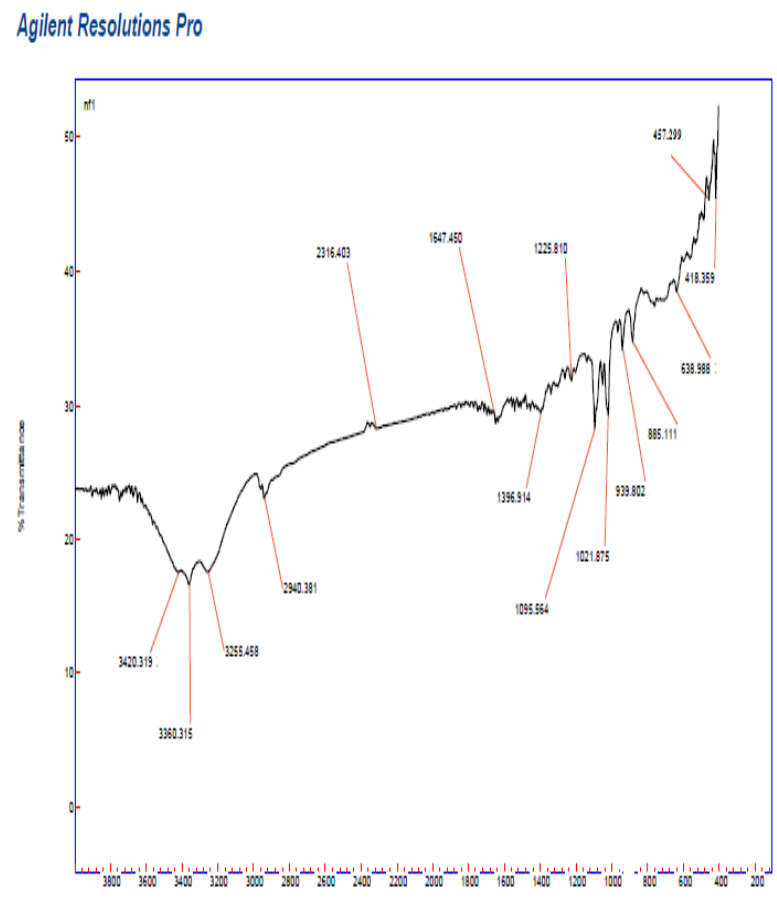

Figure 7. FTIR Spectra of Nanoformulation

prepared nanoparticles of lemon peel is in the range of stability, the nanoparticles are said to be stable. Similar result was reported with a charge of $-23 \mathrm{mV}$ of the lemon nanoparticle was obtained (George M et al., 2007). 


\subsection{Antioxidant Assays}

\subsubsection{DPPH Radical Scavenging Activity:}

LP-NF has shown the reduction in $\mathrm{IC}_{50}$ values in all the tested models and the result shows higher scavenging activity than the LPME and CS. This observation indicates that the nanoformulation is therapeutically more effective. This method uses the principle of a stable free radical (DPPH) that accepts an electron or hydrogen radical to become an overall stable molecule. The reaction of DPPH is observed by measuring the

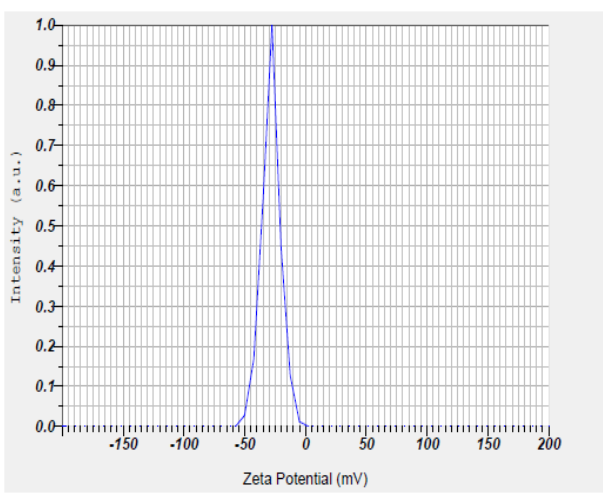

Figure 8.Zeta potential for LP-NF

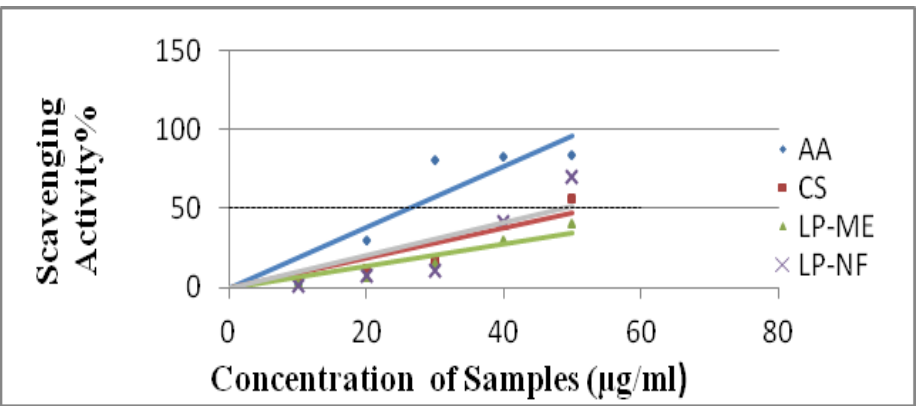

absorbance of its radical at $517 \mathrm{~nm}$. Lower the absorbance value, higher is the sample's scavenging activity. Upon reduction DPPH by an antioxidant, the absorbance at $517 \mathrm{~nm}$ disappears. The results revealed that LP-NF showed higher potency in scavenging the DPPH free radicals than pure extract of lemon peels and commercial supplement. Previous reports by Rekha S et al., 2013 also revealed enhanced scavenging activity in PVA encapsulated orange peel extracts.

Figure 9. 50\% Scavenging activity of AA,CS, LP-ME and LP-NPsample

Table 3.Antioxidant activity for AA, CS, LP-ME and LPNF5 (IC50 $\mu \mathrm{g} / \mathrm{mL}$ ) with

\begin{tabular}{|l|l|l|}
\hline S.No & Samples & IC $_{\mathbf{5 0}}$ Values \\
\hline 1. & AA & $26.032 \pm 0.21$ \\
\hline 2. & CS & $52.524 \pm 0.36$ \\
\hline 3. & LP- ME & $72.421 \pm 0.32$ \\
\hline 4. & LP-NF & $48.823 \pm 0.17$ \\
\hline
\end{tabular}

significance $(\mathrm{p}<0.05)$ 


\subsubsection{Hydrogen Peroxide Assay:}

LP-NF showed reduction in $\mathrm{IC}_{50}$ values in all the tested models and the result shows higher scavenging activity than the CS. This observation indicates that the nanoformulation is therapeutically more effective.

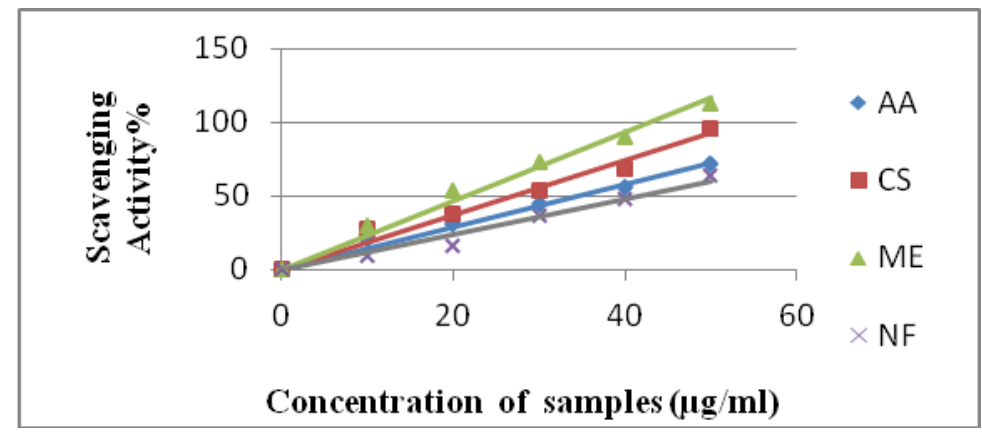

Figure 10. 50\% Scavenging activity of AA, CS, LP-ME and LPNF

Table 4. Antioxidant activity for AA, CS, LP-ME and LPNF ( $\mathrm{IC}_{50} \mu \mathrm{g} / \mathrm{mL}$ ) with significance $(\mathrm{p}<0.05)$

\begin{tabular}{|c|l|l|}
\hline S.No & Samples & IC $\mathbf{5 0}$ Values \\
\hline 1. & AA & $22.73 \pm 0.69$ \\
\hline 2. & CS & $34.47 \pm 0.32$ \\
\hline 3. & LP- ME & $41.52 \pm 0.11$ \\
\hline 4. & LP-NF & $26.99 \pm 0.18$ \\
\hline
\end{tabular}

\subsection{Antibacterial Activity:}

The biologically synthesized Lemon Peel Nanoformulation showed antimicrobial activity against E.coli (Gram-negative bacteria). The zone of inhibition was measured and tabulated. The zone of inhibition for LP-NF against $E$. coli was determined to be $18 \mathrm{~mm}$. Kokila $\mathrm{T}$ et al., 2015 reported that Citrus limon peel showed zone of inhibition of $15 \mathrm{~mm}$ against E.coli. This proves that antibacterial effect was found to be higher in nanoformulated extract.

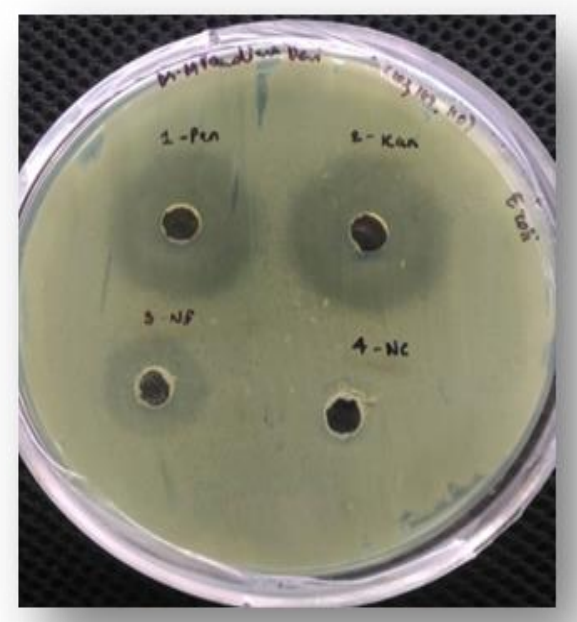

Figure 11. 50\% Scavenging activity of AA, CS, LP-ME and LPNF 
Table 5.Inhibitoryaction of LP-NF against E.coli.

\begin{tabular}{|l|l|l|}
\hline S.No. & Drug & $\begin{array}{l}\text { Zone of } \\
\text { Inhibition }\end{array}$ \\
\hline 1. & Amikacin & $25 \mathrm{~mm}$ \\
\hline 2. & Kanamycin & $28 \mathrm{~mm}$ \\
\hline 3. & LP-NF & $18 \mathrm{~mm}$ \\
\hline 4. & Negative control & - \\
\hline
\end{tabular}

\subsection{In vitro Percentage Release Study:}

LP-NF percentage release from sodium alginate beads suspended in PBS buffer at $\mathrm{pH}$ 2.1 (gastric $\mathrm{pH}$ ) and $\mathrm{pH} 7.4$ (intestinal $\mathrm{pH}$ ) is shown. The burst release of the nanoformulation was observed. It was found that $64 \%$ of the loaded drug was released in the first $7 \mathrm{~h}$. Next, a sustained drug release phase was observed that continued upto 15 hours, when $83 \%$ of the nanoformulation was released. It was reported that at $\mathrm{pH} 7.4$ and $70 \%$ of nanocurcumin from alginate beads was released (Guzman-Villanueva et al., 2013). The high release can be attributed to the presence of holes on the surface of the beads, which ease the diffusion of the release medium into thebeads loaded with LP-NF. Encapsulated bioactive compounds into nano delivery systems are being increasingly tested in food with the intention to improve the bioavailability of the hydrophobic phytocompounds. At present, biodegradable polymers are extensively used in drug delivery systems.

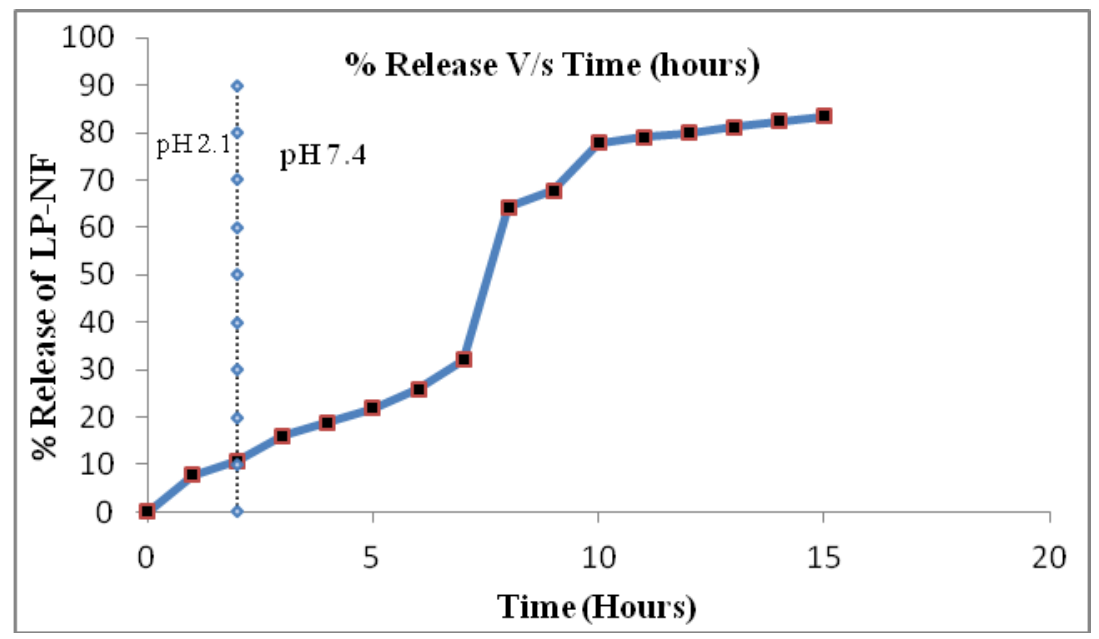

Figure 11.pH dependent release patterns of LPNF from Sodium alginate beads $(\mathrm{pH} 2.1$ and 7.4) at $37^{\circ} \mathrm{C}$

\section{Conclusions}

Lemons are a rich source of phytochemicals. Every year high amounts of lemon peels are wasted. In this project, the waste lemonpeels are converted into a valuable product. Since lemon peel extracts are poorly soluble and bioactive compounds of lemons have poor bioavailability they are loaded asnanocarriers. Biodegradable polymers are said to be a good nano carrier system for plant extracts. The antioxidant properties of lemon peel nanoformulation were determined by DPPH and hydrogen peroxide assays. The lemon peel nanoformulation showed a reduction in their $\mathrm{IC}_{50}$ values in both the assays.Well diffusion assay of LP-NF showed antibacterial activity against E.coli. In the in vitro release study of the nanoformulation, the percentage release of the nanoformulation from sodium alginate beads was calculated, and it showed a significant release after 7 
hours in PBS at $\mathrm{pH}$ 7.4.The methodology employed used for preparation of plant extract nanoformulation is very simple, easy to perform, inexpensive, and ecofriendly.This suggests that the nanoparticles system can be applied to other medicinal plants that are known to be poorly soluble and have efficacy at higher dose.

\section{References}

Anand, P., Kunnumakkara, A., Newman, R.A., Aggarwal, B.B. (2007). Bioavailability of curcumin: problems and promises. Molecular Pharmaceutics, Vol. 4, 807-818.

Asia, N., Alamgir A. (2015). Screening of Phytochemical Constituted, Antimicrobial AndAntioxidant Activities of Orange Peel (Citrus Sinensis) Extract. Bulletin of Environment, Pharmacology and Life Sciences, Vol. 4, 102-108.

Balasundram, N., Sundaram, K., Samman, S. (2006). Phenolic compounds in plants Andagri-industrial by-products: Antioxidant activity, occurrence and potential uses. Food Chemistry, Vol. 99, 191-203.

Bhakya, S., Muthukrishnan, S., Sukumaran, M., Muthukumar, M. (2016). Biogenic synthesis of silvernanoparticles and their antioxidant and antibacterial activity. Applied Nanoscience, Vol. 6, 755-766.

Chellarama, C., Murugaboopathib, G., Johna, A., Sivakumarc, R., Ganesan, S., Krithikae, S., Priyae, G. (2014).Significance of Nanotechnology in Food Industry. APCBEE Procedia, Vol. 8, $109-113$.

Chiu, Y.T., Chiu, C.P., Chien, J.T., Ho, G.H., Yang, J. and Chen, B.H. (2007). Encapsulation of lycopene extract from tomato pulp waste with gelatin and poly $(\gamma$-glutamic acid) as carrier. Journal of agricultural and food chemistry, Vol. 55(13), 5123-5130.

Cuvelier., Richard., Berset, C. (1996). Antioxidative activity and phenolic composition of pilot-plant and commercial extracts of sage and rosemary. Journal of the American Oil Chemists' Society, Vol. 73, 645-652.

Duh, P.D \& Yen, G.C. (1995). Changes in antioxidant activity and components of methanolic extracts of peanut hulls irradiated with ultraviolet light. Food Chemistry, Vol. 54, 27-131.

George, M., \& Abraham, T.E. (2007). pH sensitive alginate-guar gum hydrogel for the controlled delivery of protein drugs. International Journal of Pharmaceutics, Vol. 335, 123- 129.

Gershoff, S. 1993. Vitamin C (ascorbic acid): new roles, new requirements? Nutrition Reviews, 51(11): 313-326.

Gharsallaoui, A., Roudaut, O., Chambin.,Anand, R. (2007). Application of spray drying in microencapsulation of food ingredients: an overview. Food Research International, Vol. 40, 11071121.

Guzman-Villanueva, D., El-Sherbiny, I.M., Herrera-Ruiz, D. and Smyth, H.D. (2013). Design and in vitro evaluation of a new nano- microparticulate system for enhanced aqueous-phase solubility of curcumin. BioMed Research International, Vol. 2013, 1- 9.

Harats, D., Chevion, S., Nahir, M., Norman, Y., Sagee, O. \& Berry, B. 1998. Citrus fruit supplementation reduces lipoprotein oxidation in young men ingesting a diet high in saturated fat: presumptive evidence for an interaction between vitamins $\mathrm{C}$ and $\mathrm{E}$ in vivo.American Journal of Clinical Nutrition, 67: 240245.

Hegazy, A.E., Ibrahium, A.M. (2012). Antioxidant Activities of Orange Peel Extracts. World Applied Sciences Journal, Vol. 5, 684-688.

Jacques, P., Taylor, A., Hankinson, S., Willet, W., Mahnken, B., Lee, Y., Vaid, K. \& Lahav, M. 1997. Long-term vitamin C supplement use and prevalence of early age-related lens opacities.American Journal of Clinical Nutrition, 66: 911916.

Julkunen-Tiito, R. (1985). Phenolic constituents in the leaves of northern 
willows, methods for the analysis of certain phenolics. Journal of Agricultural and Food Chemistry, Vol. 33, 213-217.

Kaur, C., Kapoor HC. (2001). Antioxidants in fruits and vegetables- the millennium's health. InternationalJournal of Food Science and Technology, Vol. 36, 703725.

Kaur, P., Arora, M. (2013). Phytochemical Screening of orange peel and pulp. International Journal of Research in Engineering and Technology, Vol. 2, 518522.

Keles, O.S., Bakorel, A.T., and Alpanar, K. (2001). Screening of some Turkish plants for antibacterial activity. Journal of veterinary and animal sciences, Vol. 4, 559-565.

Kim, D.H. and Martin, D.C. (2006). Sustained release of dexamethasone from hydrophilic matrices using PLGA nanoparticles for neural drug delivery. Biomaterials, Vol. 27(15), 30313037.

Kokila, T.,Ramesh, S., Geetha, D. (2015).Biosynthesis of silver nanoparticles from Cavendish banana peel extract and its antibacterial and free radical scavenging assay, a novel biological approach. Applied Nanoscience, Vol.5, 911-920.

Larrauri, Sánchez-Moreno., Saura-Calixto. (1998). Effect of temperature on the free radical scavenging capacity of extracts from red and white grape pomace peels. Journal of Agricultural and Food Chemistry, Vol. 46, 2694-2697.

Leo,E.,Brina,B.,Forni, F., Vandelli, M.A. (2004). In vitro evaluation of PLA nanoparticles containing a lipophilic drug in water-soluble or insoluble form.International Journal of pharmaceutics, Vol. 278, 133-141.

Li,B.B., Smith,B.,Md. Hossain. (2006). Extraction of phenolics from citrus peels by Solvent extraction method.Separation and Purification Technology, Vol. 48, 1882- 188.

Omojate, G.C., Enwa, F.O., Jewo, AO., Eze, C.O. (2014). Mechanisms of antimicrobial actions of phytochemicals against enteric pathogens - A review. Journal of Parmaceutical, Chemical and Biological Sciences. Vol. 2, 77-85.

Poncelet., Lencki,R., Beaulieu, C., Halle, J.P., Neufeld, R.J., Fournier, A. (1992). Production of alginate beads by emulsification/ internal gelation. I. Methodology. Applied Microbiology and Biotechnology, Vol. 38, 39-45, 1992.

Prakash, D., Upadhayay, G., Singh, BN., Singh, H.B. (2007). Antioxidant and free radical - scavenging activities of seeds and agri - wastes of some varieties of soya bean (Glycine max). Food Chemistry, Vol. 104, 783- 790.

Prasad, K.N., Chew, L.Y., Khoo, H.E., Kin WengKong., AzrinaAzlan., and Ismail A. (2010). Antioxidant Capacities of Peel, Pulp, and Seed Fractions of Canariumodontophyllum Fruit. Journal of Biomedical Biotechnology, Vol. 27, 160171.

Prasad, K.N., Yang, B., Dong, X., Jiang, G., Zhang, H., Xie, H., and Jiang, Y. (2009). Flavonoid contents and antioxidant activities from Cinnamomum species: Innovative Food Science and Emerging Technologies, Vol. 10, 627- 632.

Prior, R.L., Wu, X., Schaich, K. (2005). Standardized methods for the determination of antioxidant capacity and phenolics in foods and dietary supplements.Journal of Agricultural and FoodChemistry, Vol. 53, 4290-4302.

Ramakrishna, Nannapaneni., Arunachalam, Muthaiyan., Philip, G., Crandall., Michael, G. (2008).Antimicrobial Activity of Commercial Citrus-Based Natural Extracts Against Escherichia coli $\mathrm{O} 157: \mathrm{H} 7$ Isolates and Mutant Strains. Foodborne Pathogens and Disease, Vol. 5, 695-699.

Rekha, S., Bhaskar, M. (2013).In vitro Screening and Identification of antioxidant activities of orange peel extract in different solvents. International Journal of Pharmaceutical Biological Science, Vol. 4, $405-412$. 
Rui, H., Jeanelle. (2004). Apple phytochemicals and their health benefits. Nutrition Journal, Vol. 3, 1-15.

SamidhaKamtekar, S., Keer, V., Patil, V. (2014). Estimation of Phenolic content, Flavonoid content, Antioxidant and Alpha amylase Inhibitory Activity of Marketed Polyherbal Formulation. Journal of Applied Pharmaceutical Science, Vol. 4, 61-65

Sand, D., Takada, Y. (2006). Pomegranate juice, total pomegranate ellagitannins, and punicalagin suppress inflammatory cell signaling in colon cancer cells. Journal of Agricultural Food Chemistry, Vol. 3, 980-985.

Shela, Gorinstein., Yong Seo Park. (2001).Comparison of some biochemical characteristics of different citrus fruits. Food Chemistry, Vol. 74, 309-315.

Shreedhara, C.S., Sowmya, S., Sanghai, D.B., Musmade, K.P., Koteshwara, K.B. (2017). Preparation of nanoformulation of triphala extract and evaluation of it's in vitro antioxidant and cytotoxic potential. International Journal of Pharmaceutical and Phytopharmacological Research,3(4), pp.300-305.Vol. 3(4), 300-305.

Soma Singh., Genitha Immanuel. (2014). Extraction of Antioxidants from Fruit Peels and its Utilization in Paneer. Journal of Food Processing and Technology, Vol. 5,7, DOI: 10.4172/2157-7110.1000349

Suryaprakash P., Kumar R.P., Prakash V. (2000). Thermodynamics of interaction of cafferic acid and quinicacid with multi subunit proteins. International Journal of Biological Macromolecules, Vol. 27, 219-228.

Trickler, W., \&Nagvekar. (2008). A novel nanoparticle formulation for sustained paclitaxel delivery. AAPS Pharm Sci Tech,Vol. 9, 486-493.

Wang, H., Wang, F., Tao, X., Cheng, H., (2012). Ammonia-containing dimethyl sulfoxide. An improved solvent for the dissolution of formazan crystals in the 3-
(4, 5-dimethylthiazol-2-yl)-2, 5-diphenyl tetrazolium bromide (MTT) assay. Analytical Biochemistry, Vol. 421(1), 324-326.

Wang, J., Yuan, X., Sun, B., Tian, Y., Cao, Y. (2009). Scavenging activity of enzymatic hydrolysates from wheat bran. Food Technology and Biotechnology, Vol. 47, 39- 46.

Yamaguchi, F., Yoshimura, Y., Nakazawa, H.,Ariga, T. (1999). Free radical scavenging activity of grape seed extract and antioxidants by electron spin resonance spectrometry in an $\mathrm{H}_{2} \mathrm{O}_{2}$ / $\mathrm{NaOH} /$ DMSO system. Journal of Agricultural and Food Chemistry, Vol. 47, 2544- 2548.

\section{Acknowledgements}

The authors express their sincere thanks to the HOD, DepartmentofBiotechnology, Dean, School of Bioengineering, , SRMIST, Kattakulathur for their constant support and encouragement for conducting the research. 